\title{
Reduction of Dental Decay in Rampant Caries Individuals Following Short-Term Kanamycin Treatment
}

\author{
W. J. Loesche, D. R. Bradbury, and M. P. Woolfolk \\ Dental Research Institute, School of Dentistry, The University of Michigan, \\ Ann Arbor, Michigan 48109, USA
}

A week of kanamycin gel treatment before and after the placement of dental restorations, compared to a placebo gel treatment, significantly reduced the levels of cultivable bacteria, $\mathrm{S}$ mutans and $\mathrm{S}$ sanguis, in the plaque samples collected immediately after the completion of the gel treatments, and was associated with a $46 \%$ reduction in new carious surfaces in the 14- to 37-month poriod following the gel treatment.

Dental decay caused by Streptococcus mutans can be prevented or significanly reduced in animal models by the prolonged administration of antibiotics in food and/or water. ${ }^{1}$ This treatment regimen is not applicable to human beings because of the problems associated with longterm antibiotic therapy and the impracticality of adding antibiotics to food and water for human consumption. Short-term applications of vancomycin, given topically in a gel, will lower the proportions of $S$ mutans in human plaque. ${ }^{3-4}$ When vancomycin was given daily during the school year, the Ievels of $S$ mutans and number of carious surfaces decreased slightly, but significantly, compared to a group receiving no treatment. ${ }^{5-6}$ Sliort-term application of kanamycin, given topically in Orabase, significantly reduced plaque weight and gingivitis sceres in institutionalized patients when compared with the placebo treatment. ${ }^{z}$ The plaque in the kanamycin-treated patients had significantly fewer streptococci than did the plaque in the placebo-treated group. ${ }^{8}$ In the present investigation, the effect of short-term application of kanamycin or placebo gels on the plaque levels of $S$ mutans and Streptococcus sanguis and on subsequent caries experience was assessed in children and teenagers diagnosed as having both rampant caries and elevated plaque levels of $S$ mutans.

This investigation was supported by Grant No. DE02731-10, DE-03011-08, and DE-03423-04 from the $\mathrm{Na}$ tional Institute of Dental Research.

Received for publication October 20, 1976.

Accepted for publication December 6, 1976.

\section{Materials and Methods}

Patients.-Forty-five young individuals, i.e., from 4 to 17 years old, who presented in the private practice of one of the investigators (DB) with ten or more carious surfaces were invited to participate in the study. These patients invariably did not consume fluoridated water and had a history of frequent sucrose ingestion. Approximately two to five new patients entered the study per month. Thirty-one patients compieted both weeks of gel treatment; 29 of these returned for recall appointments over the next 14- to 37-month period.

Diagnosis of CARIES - A clinical examination with an explorer and full mouth $\mathrm{x}$-ray films were used to enumerate the number of decayed surfaces at the initial visit (Table 1). Any questionable lesions were considered as carious. However, after completion of restorative and gel treatment, only sites where cavitation occurred were diagnosed as being carious. In some instances, this amounted to watching the progres-

\section{TABLE 1}

Outline of Protogol for Combined Kanamycin and Restorative Treatment in Children Diagnosed as Having Rampant Caries

1. Select patients with ten or more carious surfaces and assign to Kanamycin or placebo gel (double blind).

2. Treat for one week with gels. Take bacteriological samples from approximal and occlusal sites and from the saliva, immediately prior and after gel treatment.

3. Place dental restorations. This takes from four to seven weeks.

4. Retreat for one week with gels. Take bacteriological samples from approximal and occlusal sites and saliva immediately prior and after gel treatment.

5. Re-examination for cavitation at threemonth intervals. Take bacteriological samples as before. 
TABLE 2

Effect of Kanamycin or Placebo Gel Treatments Given for 1 Week Before and After Plagement of Dental Restorations on Levels of $S$ mutans in Plaque and Saliva

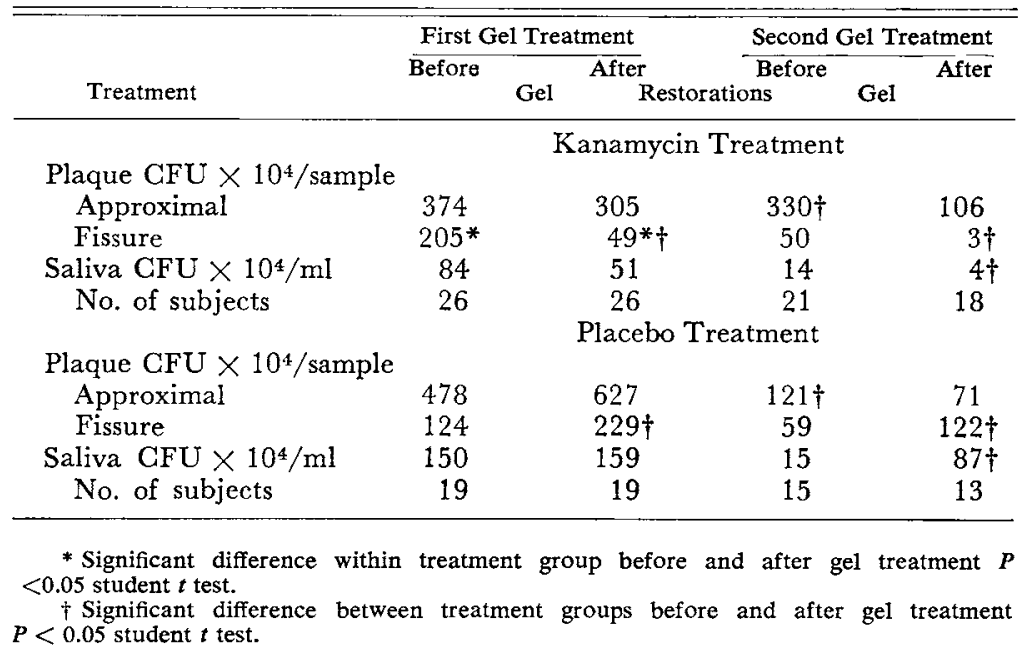

sion of a lesion over one or more recall visits to the stage where it was frankly carious.

TrEatment.-All patients received the restorative dentistry, consisting of amalgams and stainless stecl crowns, that was necessary to debride their tecth of decayed tissue. This phase of treatment took from four to seven weeks. In addition to this usual mechanical treatment, the patients were assigned, on a double blind basis, to the kanamycin or placebo gel treatment. The gel treatment was given for a one-week period immediately prior to the start of the restorative dentistry and for a second week immediately following the completion of the restorative dentistry (Table 1). The patient and/or his or her parent were shown how to apply the gel to standardized plastic trays (Fluoratray, Kerr, Romulus, Mi) and to insert the trays laden with gel into the patient's mouth. They were instructed to insert these trays for approximately five minutes in the morning after breakfast and for five minutes in the evening just before retiring. The patients were given a week's supply of gel and trays and were requested to record any noncompliance with these instructions. The actual usage of the gels was unsupervised. The patients and their parents were fully informed that they were receiving either a prescription drug or placebo drug. Approximately 10 to 15 minutes of office time was spent in this instruction and demonstration of the gel application.

The gels contained $1.4 \%$ hydroxyethyl cel- lulose, $0.24 \%$ methyl paraben, $0.04 \%$ propyl paraben, $0.2 \%$ sodium saccharin, coloring and flavoring agents and water (Davies, Rose Hoyt Pharmaceutical Co., Needham, Ma). The placebo gel was used as such, whereas 5\% kanamycin sulfate (Kantrex, Bristol Laboratories, Syracuse, NY) was added to the kanamycin gel. The kanamycin gel was prepared by stirring the powdered drug into the gel and then further dispersing with a sonifier. The gels were evaluated for their minima! inhibitory concentration against plaque bacteria periodically during the study and exhibited no loss of potency. The addition of kanamycin to the gel caused no apparent change in the taste of the gel.

BACTERIOLOGY.-The following bacteriological specimens were obtained before and after each gel treatment and at the various recall visits (Table 1). Unstimulated saliva was collected by expectoration into a wide mouth bottle and $1 \mathrm{ml}$ was placed into $9 \mathrm{ml}$ of reduced transport fluid (RTF). ${ }^{9,10}$ Fissure plaque was obtained by forcibly scratching the fissure depths of the most distal tooth in each quadrant with a sterile pointed wire held with a sterile hemostat. ${ }^{11}$ A separate wire was used to sample each of the four teeth. All four wires were placed into the same $10 \mathrm{mls}$ of RTF, so that this specimen represented a pooling of fissure plaque from the four molar areas of the mouth. Approximal plaque was collected from the most distal interproximal site in each quadrant by 
TABLE 3

Effect of Dental Restorations and Kanamycin or Placebo Gel Treatments on Total Viable Count and $S$ sanguis Count in Approximal and Occlusal Plaques

\begin{tabular}{|c|c|c|c|c|}
\hline \multirow{3}{*}{ Treatment } & \multicolumn{2}{|c|}{ First Gel Treatment } & \multicolumn{2}{|c|}{ Second Gel Treatment } \\
\hline & \multirow[t]{2}{*}{ Before } & After & \multirow[t]{2}{*}{ Before } & \multirow[t]{2}{*}{ After } \\
\hline & & & & \\
\hline & & $\begin{array}{l}\text { Kanamy } \\
\text { bunts } x\end{array}$ & reatment & \\
\hline \multicolumn{5}{|c|}{ Approximal Plaque } \\
\hline Total count & 6900 & $3290 *$ & $8550^{*}$ & $2250^{*}$ \\
\hline$S$ sanguis & 370 & 430 & 281 & $97 *$ \\
\hline \multicolumn{5}{|l|}{ Fissure Plaque } \\
\hline Total count & 1271 & $346^{*}$ & 666 & $67^{*}$ \\
\hline$S$ sanguis & 41 & 17 & 33 & $2^{*}$ \\
\hline \multirow[t]{2}{*}{ No. of subjects } & 26 & 26 & 21 & 19 \\
\hline & \multicolumn{4}{|c|}{ Placebo Treatment } \\
\hline Approximal Pla & & & & \\
\hline Total count & 10292 & $7605 *$ & $4902^{*}$ & $6628^{*}$ \\
\hline$S$ sanguis & 668 & 441 & 482 & $740^{*}$ \\
\hline \multicolumn{5}{|l|}{ Fissure Plaque } \\
\hline Total Count & 1702 & $2028^{*}$ & 892 & $805^{*}$ \\
\hline$S$ sanguis & 98 & 62 & 104 & $56 *$ \\
\hline No. of subjects & 19 & 19 & 15 & 13 \\
\hline
\end{tabular}

* Differences between groups are significantly different by student $t$ test, $P<0.05$.

means of unwaxed dental floss. ${ }^{11}$ The four separate floss samples were placed into the same $10 \mathrm{mls}$ of $\mathrm{RTF}$, so that this specimen represented a pooling of approximal plaque from the four molar areas.

All samples were brought to the laboratory within one to four hours after collection. They were dispersed for five to ten seconds by sonification, serially diluted, and appropriate dilutions plated in duplicate on MM10 sucrose agar (plaque samples) ${ }^{12,13}$ and MSB agar (plaque and salivary samples). ${ }^{14}$ The plates were incubated for four to seven days at $37 \mathrm{C}$ in an atmosphere of $85 \% \mathrm{~N}_{2}, 10 \% \mathrm{H}_{2}$, and $5 \% \mathrm{CO}_{2}$. The total colony forming units (CFU), $S$ mutans and $S$ sanguis colonies on the MM10 sucrose plates and the $S$ mutans counts on the MSB plates were enumerated. Representative $S \mathrm{mu}$ tans colonies were tested for mannitol fermentation.

STAtistics.-The $S$ mutans counts on both media and the $S$ sanguis counts on the MM10 sucrose medium were normalized as a percentage of the total CFU on the MM10 sucrose medium for each plaque sample. The $S$ mutans count in saliva was recorded per $\mathrm{ml}$ of saliva. The absolute and/or percent normalized data for the plaque and salivary samples for the 2 treatment gels were compared by computer using the MIDAS statistical programs available in the Michigan Terminal System. The data were tested for significance by both the parametric $t$ test and the nonparametric median and Kruskal Wallis Test. ${ }^{15}$

\section{Results}

The $S$ mutans counts on the MM10 sucrose agar were consistently higher than those on MSB agar. In 510 samples that were cultured on both media, the MM10 sucrose counts were noticeably higher in $46 \%$ of the comparisons, i.e., the $S$ mutans count on MM10 was at least 10 CFU higher than that on MSB agar; were approximately equal in $37 \%$ of the comparisons, i.e., the count of $S$ mutans on MM10 sucrose agar and MSB were within 10 CFU of each other; and were noticeably lower in $17 \%$ of the comparisons, i.e., the $S$ mutans count on MSB was at least 10 CFU higher than that on MM10 sucrose.

Forty-five patients received the first gel treatment and 31 received the second gel treatment. There were no complaints concerning taste of the gels and use of trays. All patients reported that they used the gels according to instructions.

The first gel treatment was given while open carious lesions were present in the mouth. The kanamycin gel lowered the levels of $S$ 
mutans in the plaques and saliva relative to the placebo gel (Table 2). This difference between groups was significant for the fissure plaques. Within the kanamycin group, the antibiotic gel caused a significant fivefold decrease in the fissure levels of $S$ mutans, but only slight decreases in the approximal and salivary levels of $S$ mutans (Table 2). Within the placebo group, the gel treatment was associated with an appreciable increase in plaque levels of $S$ mutans.

Dental restorations were placed in the patient's teeth during the next four to seven weeks. At their completion, the restorations were polished and the bacteriological samples collected. In both groups, the salivary levels of $S$ mutans had decreased to about $15 \times 10^{4}$ organisms per ml of saliva (Table 2). The approximal levels of $S$ mutans were not significantly higher in the kanamycin group, whereas the fissure levels were comparable in both groups. The gels were given for a second one-week period. The kanamycin gel reduced the approximal levels of $S$ mutans threefold, the fissure levels 16 -fold and the salivary levels fourfold relative to the before-treatment values (Table 2). The placebo gel was associated with increases in the fissure and salivary levels of $S$ mutans and a decrease in the approximal levels. The differences in fissure and salivary levels of $S$ mutans between the groups were significant. $S$ mutans could not be detected in four fissures and in three approximal samples obtained from the kanamycin group, and in one approximal sample obtained from the placebo group.

Kanamycin treatment also decreased the anaerobic viable count and the $S$ sanguis count relative to the placebo treatment (Table 3 ). This nonspecific reduction of plaque bacteria caused a shift in the proportions of $S$ mutans and $S$ sangui. n the plaque flora. In the approximal plaque samples, kanamycin treatment was associated with a significant increase in the proportions of $S$ mutans rclative to the placebo treatment (Table 4). This was due mainly to three patients who had $S$ mutans accounting from 20 to $56 \%$ of the CFU. In the fissure plaques, neither the kanamycin nor the placebo treatments seemed to affect the proportions of $S$ mutans. The percent of $S$ mutans in the approximal samples after the second period of kanamycin treatment was significantly decreased relative to samples obtained from the placebo patients.

The wide range in values obtained suggested that the data could be better analyzed by nonparametric tests of significance. The values obtained at each visit for the measured variables were ranked from low to high and

TABLE 4

Effect of Dental Restorations and Kanamycin or Plagebo Gel Treatments of Proportions of $S$ mutans and $S$ sanguis in Plaque Samples

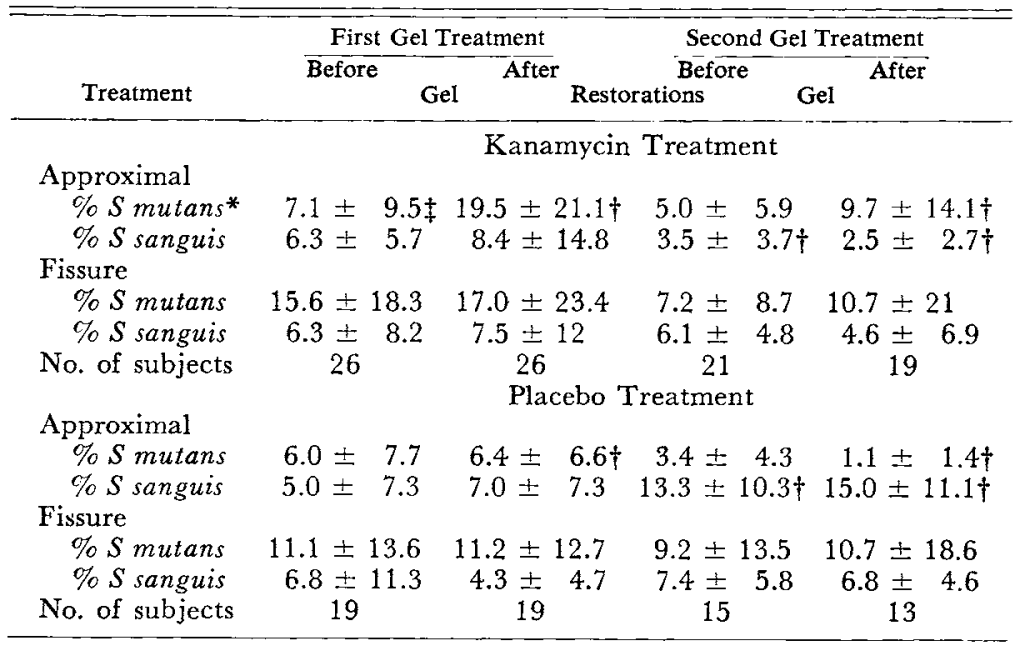

* Values given are percent of CFU on MM10 sucrose agar. When $S$ mutans could not be detected on MM10 sucrose agar, the counts of $S$ mutans on MSB agar were substituted. $\dagger$ Differences between groups are significant $P<0.05$ student $t$ test.

$\$$ Average plus or minus standard deviation. 


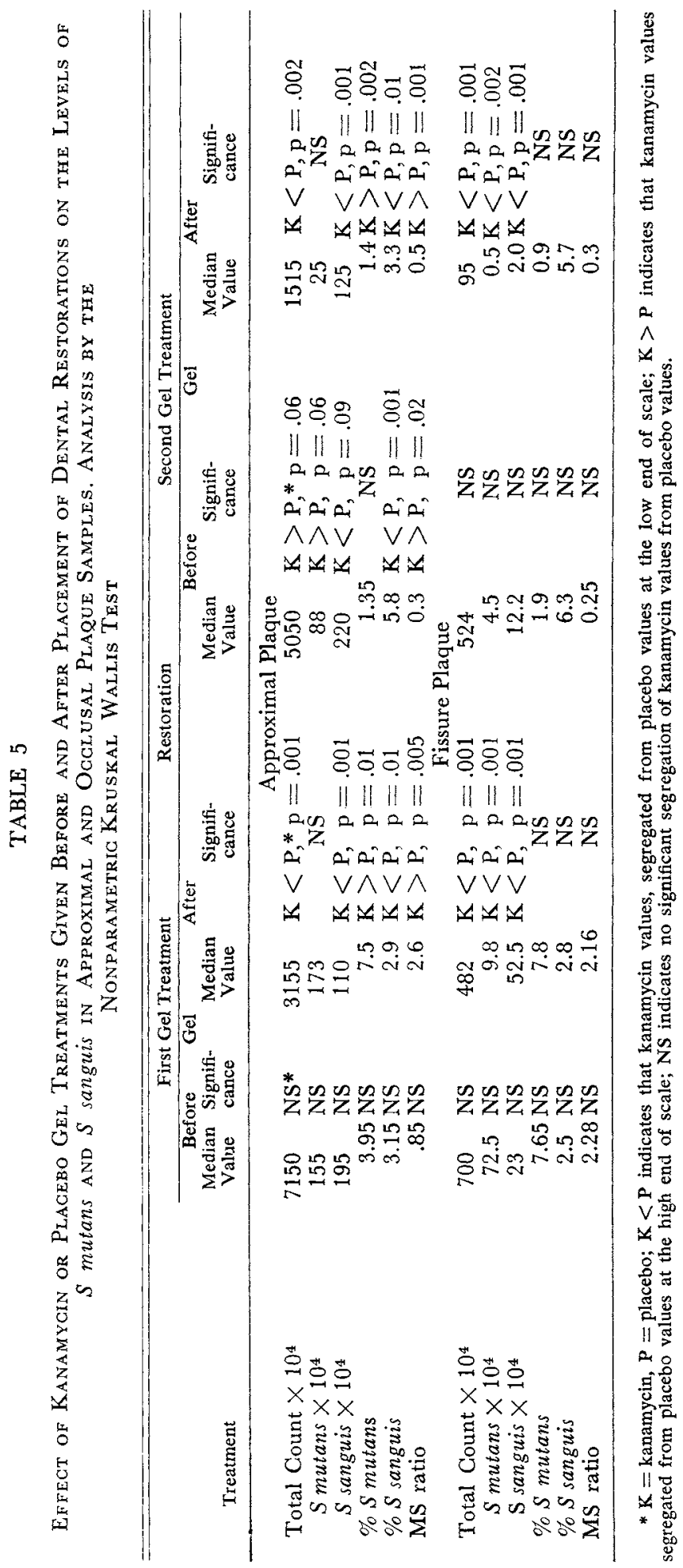


analyzed by the Kruskal Wallis Test. There were no significant differences between the kanamycin and placebo groups in any category under investigation prior to the first gel treatment (Table 5). After the first gel treatment, the total counts and $S$ sanguis counts of the approximal and fissure plaques were significantly lower in the kanamycin group. The fissure levels of $S$ mutans decreased significantly, but there was no alteration in the approximal levels. These changes resulted in a significant increase in the proportions of $S$ mutans and the mutanssanguis (MS) ratio in the approximal plaques. After the placement of dental restorations, the total count and $S$ mutans counts in the approximal plaques were significantly higher and the $S$ sanguis counts significantly lower in the kanamycin group. No significant differences were observed at this time in the fissure plaques. After the second gel treatment, all the median values decreased. The kanamycin subjects had significantly lower counts in all samples except for the $S$ mutans counts in the approximal plaques. When the percent normalized values were compared, the percent $S$ mutans and the MS ratio increased significantly and the percent $S$ sanguis decreased significantly in the approximal plaques. No changes in the proportions of $S$ mutans and $S$ sanguis were observed in the fissure plaques.

The results indicated that the kanamycin treatment was effective in reducing the bacterial count in fissure and approximal plaque samples. However, the significantly higher proportions of $S$ mutans and the higher MS ratio in approximal plaques of the kanamycin-treated subjects were considered undesirable. The clinical findings on the first few patients at the nine-month recall visit indicated that the number of new carious lesions was higher in the kanamycintreated patients. A decision was made to stop the entry of new patients into the study and to continue to observe, at recall visits, the plaque levels of $S$ mutans and $S$ sanguis as well as the new caries experience of the patients already in the study.

Twenty-nine patients returned for four or more recall visits in the 14 - to 37 -month period following the second gel treatment. There were no discernible differences at the time of entry into the study between the 16 kanamycin and the 13 placebo patients as to age, and bacteriological status (Tables 6). The number of sound surfaces at risk after the completion of the operative dentistry was remarkably similar for both groups (Table 6). The second kanamycin treatment in this group of patients had significantly reduced the plaque levels of $S \mathrm{mu}$ tans, $S$ sanguis, and other cultivable bacteria relative to the placebo treatment (Tables 7 and 8 ). However, at the two- to four-month recall visit and at all subsequent recall visits during the first year the initial differences between the groups disappeared (Tables 7 and 8 ).

\section{TABLE 6}

Characteristics at Entry into Study of 29 Subjects Who Remained in Study for At Least 14 Months After Placement of Restorations and (Gel) Treatment

\begin{tabular}{|c|c|c|}
\hline $\begin{array}{l}\text { Treatment } \\
\text { No. of Subjects } \\
\text { Age in Years }\end{array}$ & $\begin{array}{c}\text { Kanamycin } \\
16 \\
8.9 \pm 4.0^{*}(4-17) \dagger\end{array}$ & $\begin{array}{c}\text { Placebo } \\
13 \\
9.4 \pm 3.3(6-16)\end{array}$ \\
\hline Total Count $\times 10^{4}$ & \multicolumn{2}{|c|}{ Bacteriological Profile } \\
\hline Fissure & $1376 \pm 1804 * \quad(14-5750) \dagger$ & $1757 \pm 1757(49-5010)$ \\
\hline Approximal & $6066 \pm 5986(250-15900)$ & $9298 \pm 8928(670-28650)$ \\
\hline \multicolumn{3}{|l|}{$S$ mutans $\times 10^{4}$} \\
\hline Fissure & $183 \pm 313(1.9-905)$ & $152 \pm 142(0.5-385)$ \\
\hline Approximal & $295 \pm 429(5-1400)$ & $547 \pm 709(10-2125)$ \\
\hline Saliva/ml & $98 \pm 141(1.2-385)$ & $82 \pm 108(1.7-374)$ \\
\hline \multicolumn{3}{|l|}{$S$ sanguis $\times 10^{4}$} \\
\hline Fissure & $35 \pm 48(0.5-200)$ & $45 \pm 63(2-210)$ \\
\hline Approximal & $261 \pm 245(5-900)$ & $626 \pm 1423(20-5275)$ \\
\hline & \multicolumn{2}{|c|}{ Sound Surfaces at Risk After Placement of Restorations } \\
\hline Fissure & $2.5 \pm 2.6(0-9)$ & $2.5 \pm 2.5(0-7)$ \\
\hline Approximal & $33.1 \pm 10.6(10-51)$ & $34.6 \pm 8.6(21-48)$ \\
\hline Smooth & $36.4 \pm 9.6(19-54)$ & $37.2 \pm 8.7(24-48)$ \\
\hline
\end{tabular}

* Mean \pm standard deviation.

$\dagger$ Numbers in parenthesis give range of values. 
TABLE 7

Effect of Kanamygin or Plagebo Gel Treatment on Levels of $S$ mutans and $S$ sanguis in Fissure Plaques at RECALl VIsIts

\begin{tabular}{|c|c|c|c|c|c|}
\hline $\begin{array}{c}\text { Months } \\
\text { After Treatment }\end{array}$ & 0 & $2-4$ & $5-7$ & $8-10$ & $11-13$ \\
\hline & \multicolumn{5}{|c|}{ Kanamycin Treatment } \\
\hline 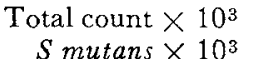 & $739^{*}$ & 5200 & 7686 & 5129 & 7546 \\
\hline MM10 & $35 *$ & $227 *$ & 332 & 643 & 643 \\
\hline MSB & $18^{*}$ & $202^{*}$ & 184 & 937 & 385 \\
\hline$S$ sanguis $\times 10^{3}$ & $21^{*}$ & 300 & 192 & 263 & 796 \\
\hline$\% S$ mutans & 7.1 & 14.8 & 4.9 & 8.8 & 11.0 \\
\hline$\% S$ sanguis & 4.6 & 5.6 & 8.9 & 5.1 & 7.9 \\
\hline \multirow[t]{2}{*}{ No. of subjects } & 16 & 10 & 10 & 12 & 15 \\
\hline & \multicolumn{5}{|c|}{ Placebo Treatment } \\
\hline $\begin{array}{r}\text { Total count } \times 10^{3} \\
S \text { mutans } \times 10^{3}\end{array}$ & $8345^{*}$ & 7070 & 9500 & 5990 & 3033 \\
\hline MM10 & $1420^{*}$ & $73^{*}$ & 350 & 338 & 591 \\
\hline MSB & $521^{*}$ & $121 *$ & 403 & 169 & 386 \\
\hline$S$ sanguis $\times 10^{3}$ & $536^{*}$ & 402 & 256 & 216 & 162 \\
\hline$\% S$ mutans & 12.4 & 6.6 & 8.0 & 10.6 & 11.6 \\
\hline$\% S$ sanguis & 6.6 & 8.1 & 5.2 & 5.2 & 4.0 \\
\hline No. of subjects & 11 & 9 & 9 & 5 & 10 \\
\hline
\end{tabular}

There was an unexplained significant decrease in fissure $S$ mutans levels in the placebo group at the two- to four-month recall visit (Table 7). Otherwise no significant differences were observed. The salivary levels of $S$ mutans ranged from 10.5 to $45.6 \times 10^{4}$ organisms $/ \mathrm{ml}$ of saliva at the various recall visits with no differences observed between the treatment groups.

The caries experience of the subjects differed according to the gel treatment. Eight of 16 kanamycin subjects and 9 of 13 placebo subjects developed carious lesions during the 14 to 37 months following gel treatment (Table 9). The three patients who developed the highest number of new carious lesions were in the placebo group. A total of 30 lesions was detected in the kanamycin-treated patients and 45 in the placebo patients. In beth groups approximately $64 \%$ of the lesions occurred on the fissure surfaces, $25 \%$ on the approximal surfaces, and $11 \%$ on the smooth surfaces (Table 10). Fissure caries were first observed in the placebo group at the six-month recall visit, and in the kanamycin group at the nine-month recall visit (Table 10). At the nine-month recall visit, the kanamycin patients had seven times the number of new carious surfaces than the placebo patients (Fig 1). Thereafter, the incidence of caries increased in the placebo group, so that after 15 to 16 months the total number of carious surfaces was higher in this group and con- tinued so for the remainder of the observation period. The placebo group averaged 3.46 carious surfaces per subject, whereas the kanamycin group averaged 1.88 carious surfaces. This represents about a $46 \%$ reduction of new carious surfaces in the kanamycin group when compared with the placebo group. This reduction was distributed among the surfaces as follows: $47 \%$ on the fissure surfaces, $41 \%$ on the approximal surfaces, and $50 \%$ on the smooth suffaces (Table 10). About $48 \%$ of the fissure surfaces at risk became carious in the kanamycin group, whereas $89 \%$ of the surfaces at risk became carious in the placebo group.

\section{Discussion and Conclusions}

The experimental protocol was based upon the specific plaque hypothesis ${ }^{2}$ that the presence of $S$ mutans in high numbers in a plaque makes that plaque cariogenic. Individuals who had such $S$ mutans dominated plaques were considered as having a specific infection that required intensive, but short-term antimicrobial treatment. A week of kanamycin gel treatment prior to and after the placement of dental restorations, compared to a placebo gel treatment, significantly reduced the levels of cultivable bacteria, $S$ mutans, and $S$ sanguis in the plaque samples collected immediately after the completion of the gel treatments, and was associ- 
TABLE 8

Effegt of Kanamycin or Placebo Gel Treatment on Levels of $S$ mutans and $S$ sanguis in Approximal Plaques at Recall Visits

\begin{tabular}{|c|c|c|c|c|c|}
\hline $\begin{array}{l}\text { Months } \\
\text { After Treatment }\end{array}$ & 0 & $2-4$ & $5-7$ & $8-10$ & $11-13$ \\
\hline & \multicolumn{5}{|c|}{ Kanamycin Treatment } \\
\hline Total count $\times 10^{4}$ & $1611^{*}$ & 3190 & 5952 & 6305 & 3852 \\
\hline MM10 & 105 & 97 & 138 & 253 & 216 \\
\hline MSB & 30 & 47 & 200 & 179 & 96 \\
\hline$S$ sanguis & $43^{*}$ & 128 & 101 & 261 & 171 \\
\hline$\%$ S mutans & 10.0 & 4.1 & 2.9 & 15.1 & 8.1 \\
\hline$\% S$ sanguis & 2.4 & 2.9 & 3.3 & 5.2 & 6.5 \\
\hline No. of subjects & 16 & 8 & 10 & 13 & 14 \\
\hline & \multicolumn{5}{|c|}{ Placebo Treatment } \\
\hline $\begin{array}{r}\text { Total count } \times 10^{4} \\
S \text { mutans } \times 10^{4}\end{array}$ & $6050^{*}$ & 6452 & 4264 & 3729 & 3374 \\
\hline MM10 & 68 & 163 & 239 & 164 & 215 \\
\hline MSB & 82 & 64 & 125 & 171 & 97 \\
\hline$S$ sanguis & $715^{*}$ & 238 & 152 & 343 & 125 \\
\hline$\% S$ mutans & 1.3 & 3.7 & 6.4 & 4.2 & 9.2 \\
\hline$\% S$ sanguis & 15.8 & 4.8 & 2.7 & 5.3 & 4.1 \\
\hline No. of subjects & 11 & 9 & 9 & 5 & 10 \\
\hline
\end{tabular}
$\mathrm{t}$ test.

* Differences between groups at each time period are significant, $P<.05$, Student

ated with a $46 \%$ reduction in new carious surraces in the 14- to 37 -months period following the gel treatment. The initial bacteriological differences between groups did not persist as there was no apparent treatment effect in the plaque or saliva samples collected at any recall visit during the first year following treatment. This would seem to indicate that the changes brought by the kanamycin treatment were inadequate to eliminate $S$ mutans, and given no other perturbations in the eco- system, such as dietary changes, the plaque levels of $S$ mutans returned with time and approached the placebo levels. This accounting does not suffice to explain how the short periods of kanamycin therapy caused the appreciable reductions in new carious lesions observed, nor why $70 \%$ of the new carious surfaces in the kanamycin group occurred by the nine-month recall visit (Fig 1). The clinical findings indicate that kanamycin treatment accelerated the rate of caries development on some surfaces,

\section{TABLE 9}

Frequency Distribution of New Garious Surfaces Seen at Recall in Patients Treated with Either Kanamycin or Placebo Gels

\begin{tabular}{|c|c|c|c|c|}
\hline \multirow[b]{2}{*}{$\begin{array}{l}\text { No. of Carious } \\
\text { Surfaces }\end{array}$} & \multicolumn{2}{|c|}{ Kanamycin } & \multicolumn{2}{|c|}{ Placebo } \\
\hline & $\begin{array}{l}\text { No. of } \\
\text { Patients }\end{array}$ & $\begin{array}{l}\text { Cumulative } \\
\text { Sum of } \\
\text { Surfaces }\end{array}$ & $\begin{array}{l}\text { No. of } \\
\text { Patients }\end{array}$ & $\begin{array}{l}\text { Cumulative } \\
\text { Sum of } \\
\text { Surfaces }\end{array}$ \\
\hline 0 & 8 & 0 & 4 & 0 \\
\hline 1 & 2 & 2 & 1 & 1 \\
\hline 2 & $\overrightarrow{1}$ & 4 & 2 & 5 \\
\hline 3 & 1 & 7 & $\overline{2}$ & 11 \\
\hline 4 & 1 & 11 & $\overline{1}$ & 15 \\
\hline 5 & 1 & 16 & - & - \\
\hline 7 & 2 & 30 & - & - \\
\hline 8 & - & - & 2 & 31 \\
\hline 14 & - & - & 1 & 45 \\
\hline Total & 16 & 30 & 13 & 45 \\
\hline
\end{tabular}


TABLE 10

New Carious Surfages Seen at Regall Visits in Patients Treated With Either Kanamyain or Plagebo Gels

\begin{tabular}{|c|c|c|c|c|c|c|c|c|c|}
\hline \multicolumn{5}{|c|}{ Kanamycin } & \multicolumn{5}{|c|}{ Placebo } \\
\hline $\begin{array}{l}\text { Patient } \\
\text { Number }\end{array}$ & $\begin{array}{l}\text { Months in } \\
\text { Study }\end{array}$ & \multicolumn{3}{|c|}{ Carious Surface } & $\begin{array}{c}\text { Patient } \\
\text { Number }\end{array}$ & $\begin{array}{l}\text { Months in } \\
\text { Study }\end{array}$ & \multicolumn{3}{|c|}{ Carious Surface $\ddagger$} \\
\hline 1 & $14 *$ & 0 & 0 & 0 & 1 & $18 *$ & $4(18)$ & $4(18)$ & 0 \\
\hline 2 & $15^{*}$ & 0 & 0 & 0 & 2 & $20 *$ & 0 & 0 & 0 \\
\hline 3 & $19 *$ & 0 & 0 & 0 & 3 & 24 & $3(6)$ & 0 & 0 \\
\hline 4 & 24 & $3(9) \dagger$ & $1(9)$ & 0 & 4 & 24 & 0 & $4(12)$ & 0 \\
\hline 5 & 31 & 0 & 0 & 0 & 5 & 26 & $8(15)$ & 0 & 0 \\
\hline 6 & 31 & $5(9)$ & $\begin{array}{l}1(15) \\
1(21)\end{array}$ & 0 & 6 & $27 *$ & 0 & 0 & 0 \\
\hline 7 & 31 & $5(15)$ & 0 & 0 & 7 & 29 & $1(16)$ & 0 & 0 \\
\hline 8 & 31 & 0 & 0 & 0 & 8 & 30 & 0 & 0 & $2(12)$ \\
\hline 9 & 31 & 0 & 0 & 0 & 9 & 31 & $6(12)$ & 0 & $1(12)$ \\
\hline 10 & 32 & 0 & $4(9)$ & $3(9)$ & & & $7(24)$ & & \\
\hline 11 & 32 & 0 & 0 & 0 & 10 & 36 & 0 & $1(15)$ & $2(15)$ \\
\hline 12 & 32 & $2(9)$ & 0 & 0 & 11 & 36 & 0 & $2(12)$ & 0 \\
\hline 13 & 34 & $2(9)$ & $1(9)$ & 0 & 12 & 36 & 0 & 0 & 0 \\
\hline 14 & 36 & $1(30)$ & 0 & 0 & 13 & 36 & 0 & 0 & 0 \\
\hline 15 & 37 & $1(12)$ & 0 & 0 & & & & & \\
\hline 16 & 37 & 0 & 0 & 0 & & & & & \\
\hline \multicolumn{10}{|c|}{ Total Carious } \\
\hline Surfac & & 19 & 8 & 3 & & & 29 & 11 & 5 \\
\hline \multicolumn{10}{|c|}{ Surfaces Per } \\
\hline Pati & & 1.19 & 0.5 & 0.19 & & & 2.23 & 0.85 & 0.38 \\
\hline $\begin{array}{r}\text { Percen } \\
\text { Red } \\
\text { Per }\end{array}$ & uction & 47 & 41 & 50 & & & & & \\
\hline
\end{tabular}

* Patient has dropped from study.

$\uparrow$ Months after gel treatment when cavitation was diagnosed

\$ Number of fissure (F), approximal (AP), or smooth (S) surfaces which became carious with time.

while preventing the development of caries on other surfaces. This paradoxical effect can be explained by a caries model which acknowledges the existence of a primary carious lesion that is not capable of being diagnosed by the clinician, and by the assumption that this primary lesion represents a focal infection or proliferation of $S$ mutans or some other organism(s) which is involved in caries formation. This primary lesion would include the zone of subsurface demineralization that is known to precede cavitation and other earlier stages of the decay process. Plaques overlying buccal surface "witite spots" have recently been shown to have higher levels of $S$ mutans than plaques taken only millimeters away from clinically normal enamel, a finding which supports the focal proliferation concept (van Houte and Duchin, personal communication).

In this model, depicted in Fig 2, the tooth surface has three situations relative to health or disease: (1) the cariesfree surface, (2) the primary lesion, and (3) the secondary lesion of obvious cavitation. Each of these surfaces will respond differently to an effectively delivered antimicrobial agent. On the cariesfree surfaces the active agent will reduce the total number of bacteria, possibly eliminating $S$ mutans as is shown in Fig 2 for kanamycin treatment. This agrees with the general reduction in viable count and $S$ mutans seen following both periods of kanamycin therapy (Tables 2 and 3 ).

In the primary lesion, an antimicrobial agent may not penetrate to the deepest layers of plaque or enter into the demineralized zones, so that a nidus of bacteria consisting of those organisms at the advancing front of the lesion will survive. In the reformation of plaque, these bacteria could grow out of the lesion and comprise a higher proportion of the plaque flora (Fig 2). In the present investigation, an enrichment for $S$ mutans was found immediately after 


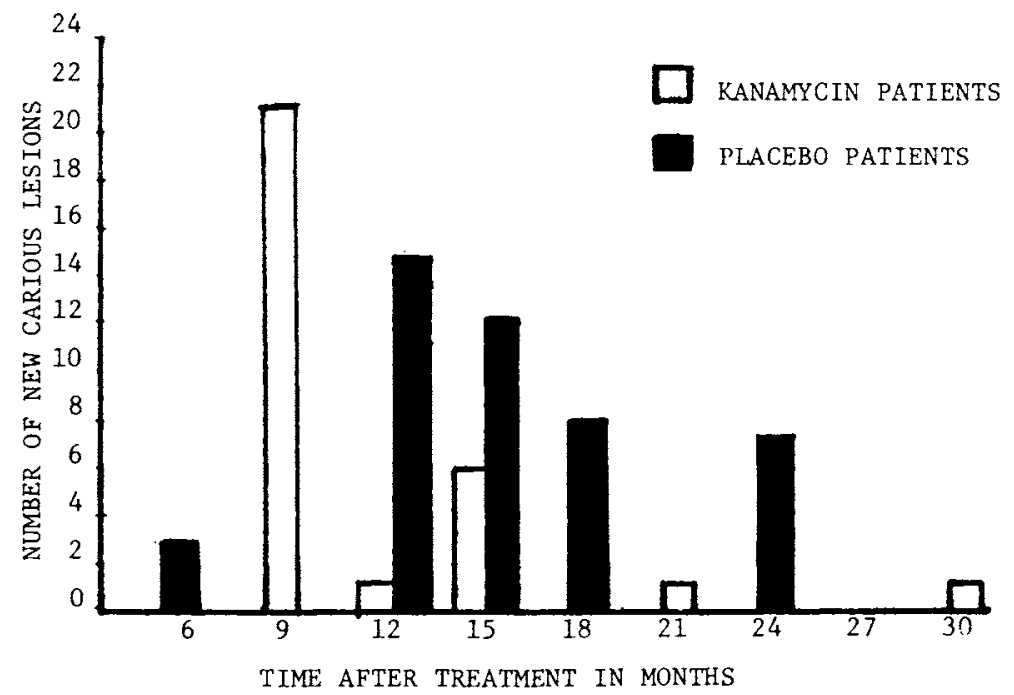

FIg 1.-Number of new carious lesions in kanamycin- or placebo-treated patients seen at recall.

kanamycin treatment, especially in the approximal plaque samples (Table 4). A similar phenomenon was not observed with the placebo treatment.

In the secondary lesion, an antimicrobial agent would behave in a manner similar to that described for the primary lesion. However, because of the cavitation associated with this lesion, it would be diagnosed as carious and debrided of carious tissue prior to the placement of a dental restoration. This should serve to re- duce the levels of total organisms as well as $S$ mutans. In the present investigation, the placement of dental restorations lowered the salivary and fissure levels of $S$ mutans in all subjects (Tables 2 and 3 ). The restorations were less effective in their ability to reduce approximal levels of $S$ mutans in the kanamycin groups, which might reflect a selection by the first kanamycin treatment of $S$ mutans in the primary lesion.

The cariesfree surfaces and primary lesions

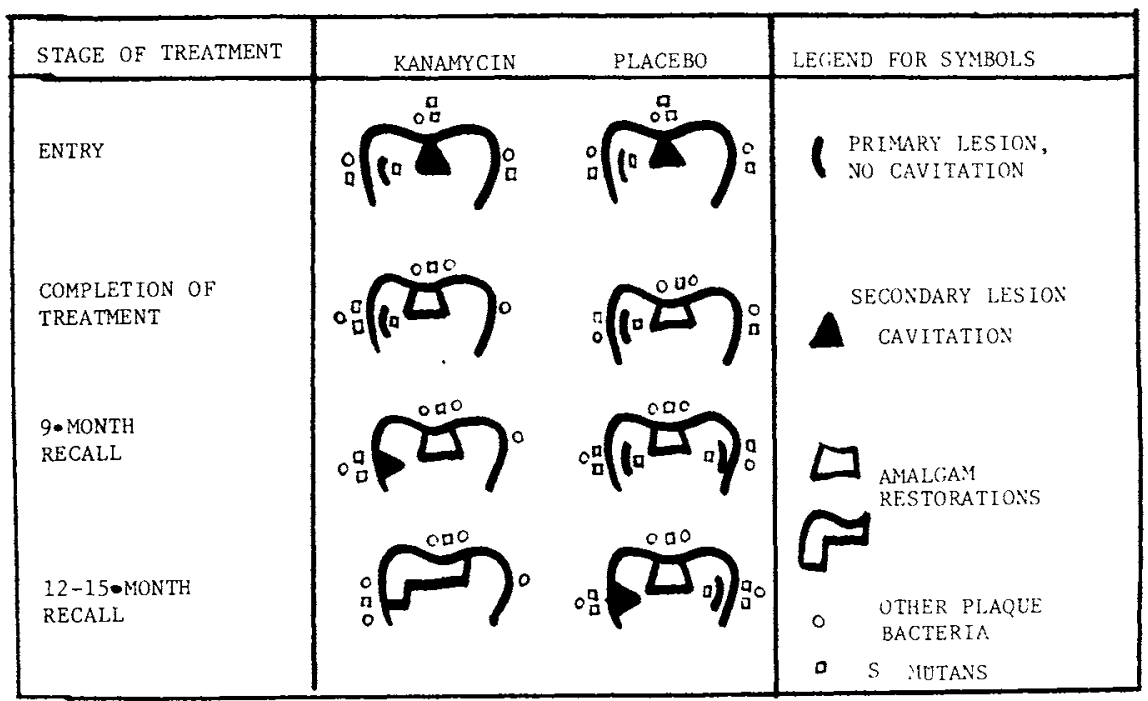

FIG 2.-Caries model to explain kanamycin effect. 
would have different $S$ mutans profiles at the completion of the restoration and gel treatments (Fig 2), which would predict different treatment outcomes during the recall period. In the kanamycin groups, the cariesfree surfaces may be rid of an $S$ mutans infection and stay that way during the recall period. Another investigation has shown that if disinfection with iodine is successful in removing $S$ mutans from a tooth surface, that surface may remain free of $S$ mutans for a considerable period of time following treatment. ${ }^{16}$ Thus, the cariesfree surfaces in the kanamycin group may remain that way because of the absence of, or low level of a $S$ mutans infection. In the placebo group, the cariesfree surfaces would still contain $S m u$ ans, and this fact might account for the eventual development of caries on these surfaces during the recall visits.

The primary lesion would also respond differently to the kanamycin or placebo treatment. The kanamycin might kill plaque organisms on the surface, but would leave unaltercd those organisms buried in the primary lesions found in fissures, and on approximal, and smooth surfaces. These residual organisms would dominate in the plaque which reforms on these surfaces, as described previously and depicted in Fig. 2. A similar selection for these organisms in the primary lesions of the placebotreated group would not occur. The net result of this selection might be an accelerated caries rate in the kanamycin group relative to the placebo group, if the surviving organisms have cariogenic potential. This indeed was the case, as the kanamycin group had seven times the number of new carious lesions at the ninemonth recall visit than did the placebo group.

This model explains some of the observations obtaincd during this investigation and provides suggestions for future chemotherapy for plaque infection. In particular, it shows how the increased proportions of $S$ mutans immediately following kanamycin gel treatment can be explained and related to subsequent accelerated caries development in the kanamycin group. The model does not state that $S$ mutans is the exclusive microbial determinant of caries. The long-term caries reduction in the kanamycin group, however, is strong evidence for a specific microbial component such as $S$ mutans in human decay.

The model indicates that antimicrobial treatment prior to the placement of dental restorations or in the presence of primary and secondary lesions will be counterproductive, as such treatment will select for organisms buried within the lesions. If these organisms have cariogenic potential, such as $S$ mutans, then an accelerated caries attack rate might ensue. The primary lesion in some, if not all cases, will be a zone of subsurface demineralization. An antimicrobial agent which is capable of penetrating into this zone might be the agent of choice. Topical flucrides promote remineralization ${ }^{17}$ and fuoride is found in elevated amounts in sites of arrested caries. ${ }^{18}$ Accordingly, we have switched to short, intensive fluoride therapy, i.e., two times a day for one week in an effort to combat new carious lesions in these rapid caries patients. Preliminary data, obtained at the sixto nine-month recall visits, indicate the neutral $1.2 \%$ sodium fluoride is causing about a 50 to $60 \%$ reduction in caries relative to a placebo group (Loesche, Pink, and Woolfolk, unpublished data).

The authors thank Rochelle Ronis for technical assistance.

\section{References}

1. FitzGerald, R.J.: Inhibition of Experimental Dental Caries by Antibiotics, Antimicrob Ag Chemother 1:296-302, 1972.

2. Loesche, W.J.: Chemotherapy of Dental Plaque Infections, Oral Sci Rev 9:63-105, 1976.

3. Jordan, H.V., and DePaola, P.F.: Effect of a Topically Applied 3\% Vancomycin Gel on Streptococcus mutans on Different Tooth Surfaces, J Dent Res 53:115-120, 1974.

4. DePaola, P.F.; JoRdan, H.V.; and Berg, J.: Temporary Suppression of Streptococcus mutans in Humans Through Topical Application of Vancomycin, J Dent Res 53:108$114,1974$.

5. Jordan, H.V., and DePaola, P.F.: Effect of Prolonged Topical Application of Vancomycin on Oral Streptococcus mutans Populations, Arch Oral Biol (In Press).

6. DePaola, P.F.; Jordan, H.V.; and SoparKAR, P.M.: Inhibition of Dental Caries in School Children by Topically Applied Vancomycin. Arch Oral Biol (In Press).

7. Loesche, W.J., and Nafe, D.: Reduction of Supragingival Plaque Accumulations in Institutionalized Down's Syndrome Patients by Periodic Treatment with Topical Kanamycin, Arch Oral Biol 18:1131-1144, 1973.

8. Loesche, W.J.; Hockett, R.N.; and Syed, S.A.: Reduction in Proportions of Dental Plaque Streptococci Following a 5-Day Topical Kanamycin Treatment, J Perio Res 12: 1-10, 1977.

9. Loesche, W.J.; Hockett, R.N.; and Syed, S.A.: The Predominant Cultivable Flora of Tooth Surface Plaque Removed from Insti- 
tutionalized Subjects, Arch Oral Biol 17: 1311-1326, 1972.

10. Syed, S.A., and Loesche, W.J.: Survival of Human Dental Plaque Flora in Various Transport Media, Appl Microbiol 24:638644, 1972.

11. Loesche, W.J.; Syed, S.A.; Murray, R.J.; and Mellberg, J.R.: Effects of Topical Acidulated Phosphate Fluoride on Percentage of Streptococcus mutans and Streptococcus sanguis in Plaque. II. Pooled Occlusal and Pooled Approximal Samples. Caries Res 9:139-155, 1975.

12. Loesche, W.J., and Syed, S.A. The Predominant Cultivable Flora of Carious Plaque and Carious Dentine. Caries Res 7:201-216, 1973.

13. Syed, S.A., and Loesche, W.J.: Efficacy of Various Growth Media in Recovering Oral
Bacterial Flora from Human Dental Plaque, Appl Microbiol 26:459-466, 1973.

14. Gold, O.; Jordan, H.V.; and vanHoute, J.A.: A Selective Medium for Streptococcus mutans, Arch Oral Biol 18:1357-1364, 1973.

15. SIEGAL, S.: Nonparametric Statistics for the Behavior Sciences, McGraw-Hill, New York, 1956.

16. Gibbons, R.J.; DePaola, P.F.; Spinelt, D.M.; and SKOBE, Z.: Interdental Localization of Streptococcus mutans as Related to Dental Caries Experience, Infect Immun 9:481-488, 1974.

17. GRON, P.: Remineralization of Enamel Lesions In Vivo, Oral Sci Rev 3:84-99, 1973.

18. Levine, R.S.: The Differential Inorganic Composition of Dentin Within Active and Arrested Carious Lesions, Caries Res 7:245$260,1973$. 